\title{
Cognitive evolution in hypertensive patients: a six-year follow-up
}

\author{
This article was published in the following Dove Press journal: \\ Vascular Health and Risk Management \\ 5 May 201I \\ Number of times this article has been viewed
}

\author{
Augusto Vicario ${ }^{1,2,3}$ \\ Mildren A del Sueldo 2,3 \\ Judith M Zilberman ${ }^{2,3}$ \\ Gustavo H Cerezo ${ }^{2,3}$ \\ 'Department of Internal Medicine, \\ Cardiovascular Division, Hospital \\ Español de Buenos Aires, Argentina; \\ ${ }^{2}$ Argentine Federation of Cardiology, \\ (AFC), Buenos Aires, Argentina; \\ ${ }^{3}$ Research Group, Human Health \\ Commission, CERTUS Foundation, \\ Buenos Aires, Argentina
}

Background: Several studies have examined the links between hypertension, vascular damage, and cognitive impairment. The functions most commonly involved seem to be those associated with memory and executive function.

Aims: 1) to report the cognitive evolution in a cohort of hypertensive patients, 2) to identify the affected domains, and 3) to correlate the results obtained with blood pressure measurements.

Materials and Methods: Observational 6-year follow-up cohort study including both males and females aged $\geq 65$ and $\leq 80$ years, and hypertensive patients under treatment. Patients with a history of any of the following conditions were excluded: stroke, transient ischemic attack, diabetes mellitus, atrial fibrillation, cardiac surgery, dementia, or depression. Four neurocognitive evaluations were performed (at baseline and every 2 years). The tests used evaluated memory and executive function domain. Blood pressure was measured on every cognitive evaluation.

Results: Sixty patients were followed for $76.4 \pm 2.8$ months. The average age at baseline was $72.5 \pm 4.2$ and $77.9 \pm 4.6$ at 6 years $(65 \%$ were women). Two patients were lost to follow up $(3.3 \%)$ and 8 patients died (13.3\%).The density incidence for dementia was $0.6 \%$ patients per year $(\mathrm{pt} / \mathrm{y})(\mathrm{n}=3)$ and for depression was $1.6 \% \mathrm{pt} / \mathrm{y}(\mathrm{n}=12)$. No changes were observed in either memory impairment or the Mini Mental State Examination (MMSE) results $(p=n s)$ during follow-up. A progressive impairment of the executive function was shown regardless of the blood pressure measurements.

Conclusion: 1) the incidence of dementia doubled to general population, 2) the initial memory impairment did not change during the evaluation period, 3) cognitive impairment worsened in the areas related to executive function (prefrontal cortex) regardless of the adequacy of antihypertensive treatment and blood pressure values.

Keywords: hypertension, cognitive impairment, frontal lobe, dementia, executive function

\section{Introduction}

We have already described the difference between cognitive "impairment", and the cognitive "decline" typically observed during aging, and concluded that in hypertensive patients the most commonly involved cognitive domains were long-term memory and executive functioning. ${ }^{1}$ There is clear evidence that hypertension produces many pathological changes in the vascular system. Because it affects the brain, hypertension is the most important risk factor for stroke. ${ }^{2}$ Apart from this complication, however, high blood pressure may damage the brain blood vessels, cause white matter lesions, and lead to both cortical and subcortical volume loss. These conditions may cause cognitive impairment, vascular dementia and, in some cases, even contribute to the progression of Alzheimer's disease. Due to the long-term subclinical nature of these
Correspondence: Augusto Vicario Department of Internal Medicine, Cardiovascular Division, Hospital Español de Buenos Aires, Argentina, 2975 Belgrano Ave, 1209 Buenos Aires, Argentina

Tel/Fax +54 0 I I 47756766

Cell +5401 I I5 6122 989I

Email augusto.vicario@gmail.com 
conditions, it is essential to use neuropsychological tests to study them. ${ }^{3,4}$ The increasing interest in the prevention, early detection, and management of cognitive impairment is the foundations of our investigation. The aims of this study were to observe the cognitive evolution, initially impaired, in our sample of hypertensive patients for 6 years, and to correlate our results with the blood pressure values (achieved therapeutic goals) and anti-hypertensive medications used.

\section{Materials and methods}

During the recruitment phase for 5 months, between December 2001 and April 2002, all patients seen in the outpatient cardiology clinic of the Hospital Español in Buenos Aires, Argentina, were invited to participate in the trial if they met the inclusion criteria. Both male and female patients $\geq 65$ years of age with a hypertension diagnosis were included in this study. Individuals with a history of neurologic disease (stroke, transitory ischemic attack), psychiatric disease (depression or dementia according to the Diagnostic and Statistical Manual of Mental Disorders (DSM-IV), ${ }^{5}$ metabolic disease, diabetes mellitus (according to the standard of the American Diabetes Association), ${ }^{6}$ dislipemia (defined as the use of cholesterol-lowering drugs, low-density lipoprotein $>160 \mathrm{mg} / \mathrm{dL}$, or nonhigh-density lipoprotein $>190 \mathrm{mg} / \mathrm{dL}$ ), and cardiovascular disease (heart failure, atrial fibrillation and cardiac surgery), as well as those on cholinesterase inhibitors, glutamatergic or antipsychotic inhibitors, were excluded. Sixty caucasian patients out of 520 consecutive patients signed an informed consent to participate in a 6-year follow-up trial. Hypertension was defined as systolic blood pressure (SBP) $\geq 140 \mathrm{~mm} \mathrm{Hg}$ and/or diastolic blood pressure (DBP) $\geq 90 \mathrm{~mm} \mathrm{Hg}$ at office visit and/or on three occasions throughout their clinical history or if they were taking specific antihypertensive medication. Blood pressure (BP) was measured according to both national and international guidelines, ${ }^{7,8}$ together with each cognitive evaluation. The anti-hypertensive medication was not modified during follow-up. Other clinical conditions (cardiac diseases, cerebral diseases, etc) were recorded. In the benzodiazepinetreated group, benzodiazepine was discontinued 72 hours before each cognitive evaluation. The trial was approved by an Independent Ethics Committee (IEC), pursuant to international Good Clinical Practice (GCP), the local regulations, and the Declaration of Helsinki and its amendments.

The neuropsychological assessment battery used in our Center included the following test: a) Folstein's Mini Mental Statement Examination (MMSE) ${ }^{9}$ cut-off point $24,{ }^{10}$ b) New York University (NYU) Paragraph Test to evaluate both short and long-term memory, ${ }^{11} \mathrm{c}$ ) Trial Making Test ${ }^{12}$ parts A and B (TMT A and B), d) the clock drawing test, ${ }^{13}$ e) Stroop Test (Colors and Words), ${ }^{14}$ and g) before each assessment patients answered a "Hospital Anxiety-Depression Scale" (HAD) questionnaire to evaluate whether the anxiety and/or depression - two conditions that alter the cognitive results - were present. ${ }^{15}$ These tests were administered by neuropsychologists at the beginning of the study and then every 2 years.

\section{Study design and statistics}

This is an observational, cohort, 6-year follow up study. The SPSS 17.0 statistic package was used. While the categorical variables are expressed in percentages, the continuous variables are expressed with mean \pm standard deviation (SD). For paired samples, the $t$-test was used. For analysis of variance, ANOVA was used, either parametric or nonparametric Kruskall-Wallis when the distribution was not gaussian or the test used points. The statistical tests were performed for a significance level $<0.05$.

\section{Results}

The general baseline characteristics of the group, blood pressure, schooling, age ( $72.5 \pm 4.2$ years) and the proportion of patients by gender (women $56.6 \%$ vs $65 \%$ ), were included in Table 1. After 6 years of follow-up, the average age of the hypertensive patients was $77.9 \pm 4.6$ years. At the time of enrollment $28.3 \%$ of the hypertensive patients were not

Table I General characteristics of the hypertensive patients

\begin{tabular}{|c|c|c|}
\hline \multirow[t]{2}{*}{ Variable } & \multicolumn{2}{|c|}{ Hypertensive patients $(n=60)$} \\
\hline & $\bar{n}$ & $\%$ \\
\hline Age $(y)^{\prime}$ & \multicolumn{2}{|c|}{$72.5 \pm 4.2$} \\
\hline Female & 39 & 65 \\
\hline \multicolumn{3}{|l|}{ Schooling level } \\
\hline Grammar school & 35 & 58.3 \\
\hline High-school & 20 & 33.3 \\
\hline College studies & 5 & 8.3 \\
\hline \multicolumn{3}{|l|}{ Blood pressure (BP) ${ }^{2}$} \\
\hline Systolic BP & \multicolumn{2}{|c|}{$141.4 \pm 17.8$} \\
\hline Diastolic BP & \multicolumn{2}{|c|}{$80.8 \pm 9.02$} \\
\hline Pulse pressure & \multicolumn{2}{|c|}{$60.5 \pm 16.6$} \\
\hline Obesity $^{3}$ & 10 & 16.6 \\
\hline \multicolumn{3}{|l|}{ Smoking } \\
\hline Nonsmokers ${ }^{4}$ & 50 & 83.3 \\
\hline Smokers & 10 & 16.6 \\
\hline \multicolumn{3}{|l|}{ Cardiopathy } \\
\hline Coronary pathology & 7 & 11.6 \\
\hline Arrhythmia $^{5}$ & 12 & 20 \\
\hline Psychotropics use ${ }^{6}$ & 27 & 45 \\
\hline
\end{tabular}

Notes: Age: years, $x \pm \mathrm{DE}$;' $\mathrm{BP}: \mathrm{mm} \mathrm{Hg}{ }^{2}$ obesity: body mass index $\geq 30 \mathrm{~kg} / \mathrm{m} ;{ }^{2,3}$ smoking: had never smoked or had not smoked for more than a year, ${ }^{4}$ arrhythmia: extrasystoles supra and/or ventricular; ${ }^{5}$ psychotropics: benzodiazepines. ${ }^{6}$ 
controlled and hypertension had been present for $10.2 \pm 8.2$ (range, 5-30) years. The evolution of the cognitive domains studied (average $\pm \mathrm{SD}$ ) after $76.4 \pm 2.8$ months of follow-up is shown in Table 2. During follow-up, 2 patients were lost to follow up (3.3\%) and 8 patients died (13.3\%) (Table 3 ). Three patients developed dementia (density incidence $0.6 \%$ $\mathrm{pt} / \mathrm{y}$ ) and were excluded from the following neuropsychological tests. The depression density incidence was $1.6 \% \mathrm{pt} / \mathrm{y}$ $(n=12)$. Patients with depression were treated and none had clinical signs at the time of evaluation. Memory impairment both in the short and long term remained unchanged during follow-up (baseline short-term memory $4 \pm 2.1$ vs final short-term memory $5 \pm 2.4$, pt $=\mathrm{ns}$; basal long-term memory $6 \pm 2.5 \mathrm{vs}$ final long-term memory $6 \pm 2.8, \mathrm{pt}=\mathrm{ns}$ ). Throughout follow-up the results of the MMSE were normal (baseline $28 \pm 1.6$ vs final points $29 \pm 2.2$, pt $=\mathrm{ns}$ ). A more marked impairment was observed in tests evaluating executive function. Performance in the Stroop test decreased throughout the follow-up showing more interference (basal results $-0.6 \pm 5.8$ vs final results $-2.3 \pm 8.6, P=0.031$ ) (Figure 1). The capacity to perform TMT part B progressively decreased showing statistical significance at 4 years compared with the basal result $(16.6 \%[n=10]$ vs $38.2 \%(n=18)$, $\mathrm{pt}=0.033)$, whereas after 6 years the downward tendency was $(16.6 \%[n=10]$ vs $34 \%[n=16], p t=0.061)$ (Figure 2$)$. The results of the cognitive tests showed no relationship with SBP or DBP values or pulse pressure (PP). The antihypertensive treatment was not modified by the investigators. When compared the cognitive performance with the different classes of antihypertensive drugs, used in monotheraphy or combined therapy, no differences were shown.

\section{Discussion}

The relationship between the vascular damage caused by hypertension in brain structures, and the development of cognitive disorders and/or dementia several years later, has been widely investigated in epidemiological longitudinal studies. ${ }^{16-23}$ However, not all cognitive domains are equally affected by hypertension. In previous observations we showed that the executive functions related to the prefrontal cortex in hypertensive patients were more affected than those of patients with normal blood pressure. ${ }^{1}$

The vulnerability to hypoxia and cerebral hypoperfusion is not homogenous in all regions of the brain. ${ }^{24}$ The frontal lobes - particularly the prefrontal cortex - are more vulnerable to aging and even more to the effects of hypertension because of their phylogenetically younger structures. ${ }^{25}$

A study of frontal function in hypertensive nonhuman primates (rhesus Macaque mulatta monkeys) concluded that in this model of cerebral vascular damage, the abstraction capacity and the executive function were both altered compared with frontal function in nonhypertensive monkeys. ${ }^{26}$ Sabatini et al observed that anti-hypertensive treatment with different calcium antagonists increased the cellularity of all layers of the prefrontal cortex in spontaneously hypertensive rats (SHR). ${ }^{27}$

The frontal lobes, representing $29 \%$ of the cortex and the most advanced functions of the brain, called executive functions, depend on the integrity of this lobes. ${ }^{28}$ Three-way circuits connecting the frontal lobes with the subcortex structures and clinical behavioral syndromes depend on the damaged circuit. ${ }^{29}$ In our study, the hypertensive patients showed a progressive impairment of executive function during the years studied, reflected by means of the TMT-B and the Stroop test.

The activity of the frontal lobes is strictly related to blood flow. ${ }^{30}$ These regional brain flow changes are clearly visible in hypertensive patients, which affects their cognitive performance; it seems that, with the passing of time, the duration of hypertension contributes significantly to these changes. ${ }^{24,31}$ However, in the same way that the loss of secondary vasomotor capacity in hypertensive disorders leads to the redistribution of blood flow as a mechanism of adaptation, cognitive activities also use these mechanisms

Table 2 Cognitive evolution during the follow-up

\begin{tabular}{|c|c|c|c|c|c|}
\hline Variable & Basal $(n=60)$ & 2 years $(n=5 I)$ & 4 years $(n=47)$ & 6 years $(n=47)$ & $P$ value \\
\hline Systolic BP (mm Hg) & $140 \pm 16.5$ & $140 \pm 17.3$ & $146.5 \pm 19.9$ & $|48 \pm 2| .4$ & ns \\
\hline Diastolic BP (mm Hg) & $80 \pm 8.4$ & $80 \pm 8.6$ & $80 \pm 9.8$ & $85 \pm 8.9$ & ns \\
\hline Pulse pressure & $60 \pm 15$ & $60 \pm 15.6$ & $60 \pm 16,8$ & $64 \pm 18.2$ & ns \\
\hline MMSE & $28 \pm 1.6$ & $29 \pm 1.0$ & $29 \pm 1.1$ & $29 \pm 2.2$ & ns \\
\hline Short-term memory & $4 \pm 2.1$ & $5 \pm 2.8$ & $4 \pm 2.2$ & $5 \pm 2.4$ & ns \\
\hline Long-term memory & $6 \pm 2.5$ & $8 \pm 3.8$ & $6 \pm 3.0$ & $6 \pm 2.8$ & ns \\
\hline TMT-B nonexecution & $10(16.6 \%)$ & $12(23.5 \%)$ & $18(38.2 \%)^{*}$ & $16(34.0 \%)$ & $=0.061$ \\
\hline Stroop test & $-0.6 \pm 5.8$ & $-0.9 \pm 5.9$ & $-1.2 \pm 6.6$ & $-2.3 \pm 8.6$ & $=0.013$ \\
\hline
\end{tabular}

Note: $* P=0.033$ vs baseline.

Abbreviations: BP, blood pressure; MMSE, Mini Mental State Examination; TMT-B, Trial Making Test part B. 
Table 3 Mortality causes

\begin{tabular}{lll}
\hline Causes & N & \% of total deaths \\
\hline Cardiac disease & & 50 \\
$\quad$ Heart failure & 2 & \\
Myocardial infarction & $\mathrm{I}$ & \\
$\quad$ Sudden death & $\mathrm{I}$ & 25 \\
Stroke & & \\
$\quad$ Cerebral aneurysm & $\mathrm{I}$ & \\
$\quad$ Cerebral hemorrhage & $\mathrm{I}$ & 25 \\
Oncologic disease & \\
$\quad$ Leukemia & $\mathrm{I}$ & \\
Endometrial cancer & $\mathrm{I}$ & \\
\hline
\end{tabular}

in order to perform complex activities with limited blood flow. Likewise, cognitive deficits are difficult to detect using conventional tests and subclinical disorders occur within years. This may explain why the MMSE, a low sensitivity and low specificity though useful test, did not change during follow-up. Consequently we had to use specific tests able to detect failure in executive functions.

On the other hand, the basal long-term memory impairment did not show a negative evolution during follow-up, despite being one of the first cognitive domains involved and it is the most common chief complaint in this type of patients. ${ }^{32}$

A possible hypothesis for these associations in hypertensive patients is probably due to the direct consequences of the demyelinization (caused by hypoxia and consecutive ischemia), ${ }^{23}$ and may cause the "disconnection" of subcortical-cortical loops. ${ }^{33,34}$ This lack of communication between the dorsolateral prefrontal cortex and the nuclei of the base by means of the caudate nucleus may be responsible for the "executive dysfunction".

Depression is a common and under diagnosed symptom in elderly people, characterized mainly by cognitive symptoms (including slow thinking and volition-affected behaviour), which depend on the integrity of the frontal lobes and make

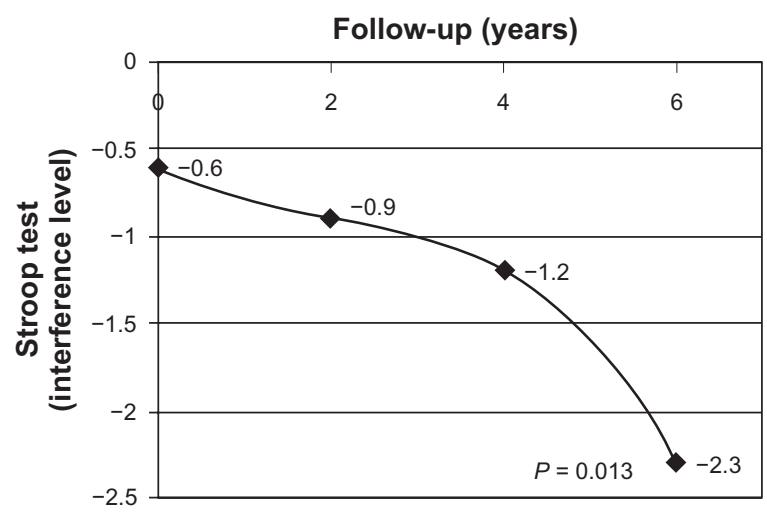

Figure I Stroop test change during follow-up (expressed as a level of interference between colors and words).

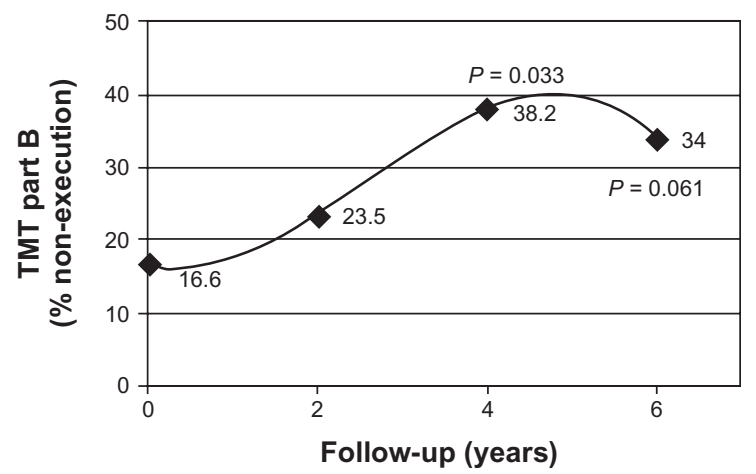

Figure 2 Trial Making Test part B change during follow-up (expressed as \% of patients who did not perform the test).

the mind rigid. ${ }^{35}$ However, the density incidence for depression is within the expected range in patients $>65$ years old $(1.6 \% \mathrm{pt} / \mathrm{y}),{ }^{36}$ whereas the incidence density for dementia doubled compared with the general population $(0.6 \% \mathrm{pt} / \mathrm{y})$. Many of the cohorts studied have no selective screening for cardiovascular diseases that may appear as confounders or disparities related to the schooling. Our cohort though small has been carefully classified and followed for a reasonable time in order to observe cognitive changes.

Lastly, the blood pressure values during follow-up show a group of well-controlled patients, despite the fact that cognitive impairment grew worse and, although the sample is small no differences were observed in cognitive tests when analyzing patients according to BP values divided into controlled ( $\leq 139 \mathrm{and} /$ or $\leq 89 \mathrm{mmHg}$ ) and noncontrolled $(\geq 140$ and/or $\geq 90 \mathrm{mmHg}$ ). This result also shows the need to do systematic neuropsychological screening when hypertensive patients are clinically examined so as to detect a possibly very narrow "window space" to intervene and stop the progression of cognitive impairment. We did not notice any changes in length of time of the disease or class of anti-hypertensive drugs used.

For a long time now, frontal lobes were called silent lobes. It is beyond doubt that hypertension is a risk factor for cognitive impairment, dementia, and/or depression. Both memory and executive functions seem to become impaired more often. The "dys-executive" syndrome (prefrontal domains) appears prematurely and its evolution seems to be progressive compared with memory, which seems to be affected more slowly. The unfavorable cognitive evolution does not seem to be related to the BP values or the antihypertensive treatments.

\section{Acknowledgment}

We thank Jonathan Feldman for the translation of this article and CERTUS Research Group for their invaluable assistance. 


\section{Disclosure}

This work was not supported financially by any institution and the authors declare no competing interests.

\section{References}

1. Vicario A, Martinez CD, Barreto D, Díaz Casale A, Nicolosi L. Hypertension and cognitive decline: impact on executive function. J Clin Hypertens. 2005;7:598-604.

2. Lewington S, Clarke R, Qizilbach N, et al. Prospective Study Collaboration. Age-specific relevance of usual blood pressure to vascular mortality: a meta-analysis of individual data for one million adults in 61 prospective studies. Lancet. 2002;360:1903-1913.

3. Vicario A, Martinez CD. Evaluación del daño funcional del cerebro en pacientes hipertensos: empleo de un Examen Cognitivo Minimo. Rev Fed Arg Cardiol. 2007;36:146-151. http://www.fac.org.ar/1/ revista/07v36n3/art_orig/art_ori01/vicario.pdf. Accessed April 21, 2011.

4. Vicario A., Cerezo GH, Taragano FE, Allegri R, Sarasola D. Evaluación, Diagnóstico y Tratamiento de los Trastornos Cognitivos en pacientes con Enfermedad Vascular. Recomendaciones para la práctica clínica 2007. Rev Fed Arg Cardiol. 2007;36(Suppl 3):S1-S30. http://www.fac.org. ar/1/revista/07v36n2/gral/supl3_07.PDF. Accessed April 21, 2011.

5. American Psychiatric Association. Diagnostic and Statistical Manual of Mental Disorders. 4th ed. Washington, DC: American Psychiatric Association Press; 1994.

6. Expert Committee on the Diagnosis and Classification of Diabetes Mellitus. Report of the expert committee on the diagnosis and classification of diabetes mellitus. Diabetes Care. 2000;23(Suppl 1): S4-S19.

7. Mancia G, De Backer G, Dominiczak A, et al. Authors/Task Force Members. 2007 ESH-ESC Practice Guidelines for the Management of Arterial Hypertension: ESH-ESC Task Force on the management of Arterial Hypertension. J Hypertens. 2007;25:1751-1762.

8. Consenso de Hipertensión Arterial. Consejo Argentino de Hipertensión Arterial Dr. Eduardo Braun Menéndez. Rev Argent Cardiol. 2007; 75(Suppl 4):S1-S43.

9. Folstein MF, Folstein SE, McHugh PR. "Mini-mental stat". A practical method for grading the cognitive state of patients for the clinician. J Psychiatr Res. 1975;12:189-198.

10. Allegri RF, Ollari JA, Mangone CA, et al. El Mini Mental State Examination en la Argentina: Instrucciones para su administración. Rev Neurol Arg. 1999;24:31-35.

11. Ferris $\mathrm{S}$, et al. NYU computerized test battery for assessing cognition in aging and dementia. Psychopharmacol Bull. 1988;4:699-702.

12. Lezak MD, Howieson DB, Loring DW. Neuropsychological Assessment. 4th ed. New York: Oxford University Press; 2004.

13. Freedman M, Leach K, Kaplan E, et al. Clock Drawing: SA Neuropsychological Analysis. New York. NY: Oxford University Press; 1994.

14. Golden CJ. Stroop Color and Word Test. A Manual for Clinical and Experimental Uses. Wood Dale, Illinois: Stoelting; 1978.

15. Wilkinson MJB, et al. Psychiatric screening in general practice: comparison of the general health questionnaire and the hospital anxiety depression scale. J R Coll Gen Pract. 1988;38:311-313.

16. Wilkie F, Eisdofer C. Intelligence and blood pressure in the aged. Science. 1971;172:959-962.

Vascular Health and Risk Management

\section{Publish your work in this journal}

Vascular Health and Risk Management is an international, peerreviewed journal of therapeutics and risk management, focusing on concise rapid reporting of clinical studies on the processes involved in the maintenance of vascular health; the monitoring, prevention and treatment of vascular disease and its sequelae; and the involvement of
17. Elias F, Wolf PA, D'Agostino RB, Cobb J, White LR. Untreated blood pressure level is inversely related to cognitive functioning: the Framingham Study. Am J Epidemiol. 1993;138:353-364.

18. Launer LJ, Ross GW, Petrovich H, et al. Midlife blood pressure and dementia: Honolulu-Asian Aging Study. Neurobiol Aging. 2000;21: $49-55$.

19. Guo Z, Fratiglioni L, Winblad B, Viitanen M. Blood pressure and performance on the Mini-Mental State Examination in the very old. Cross-sectional and longitudinal data from the Kungsholmen Project. Am J Epidemiol. 1997;145:1106-1113.

20. Kilander L, Nyman H, Boberg M, Hansson L, Lithell H. Hypertension is related to cognitive impairment: a 20-year follow-up of 999 men. Hypertension. 1998;31:780-786.

21. Skoog I, Lernfelt B, Landahi S, et al. Fifteen-year longitudinal study of blood pressure and dementia. Lancet. 1996;347:1141-1145.

22. De Leeuw FE, de Groot JC, Oudkerk M, et al. Hypertension and white matter lesions in a prospective cohort study. Brain. 2002;125: $765-772$.

23. Vermeer Se, Prins ND, den Heijer T, et al. Silent brain infarctions and the risk of dementia and cognitive decline. $N$ Engl J Med. 2003;348: $1215-1222$.

24. Beason-Held LL, Moghekar A, Zonderman AB, Kraut MA, Resnick SM. Longitudinal changes in cerebral blood flow in the older hypertensive brain. Stroke. 2007;38:1766-1773.

25. Jackson J. On some implications of dissolution of the nervous system. London Medical Press and Circular. 1882;2:411-414.

26. Moore TL, Killiany RJ, Rosene DL, Prusty S, Hollander W, Moss MB Impairment of executive function induced by hypertension in the rhesus monkey (Macaca mulatta). Behav Neurosci. 2002;116:387-396.

27. Sabbatini M, Tomassoni D, Amenta F. Hypertensive brain damage: comparative evaluation of protective effect of treatment with dyhridopyridine derivatives in spontaneously hypertensive rats. Mech Aging Dev. 2001;122:2085-2105.

28. Goldberg E. The conductor: A closer look at the frontal lobes. In: Goldberg E, editor. The Executive Brain. Frontal Lobes and the Civilized Mind. (1st ed.) New York: Oxford University Press; 2001:69.

29. Cummings JL. Frontal-subcortical circuits and human behavior. Arch Neurol. 1979;50:873-880.

30. Brown GG, Clark CM, Liu TT. Measurement of cerebral perfusion with arterial spin labeling: part 2. Applications. J Int Neuropsychol Soc. 2007;13:1-13.

31. Dai W, Lopez OL, Carmichael OT, Becker JT, Kuller LH, Gach M. Abnormal regional cerebral blood flow in cognitively normal elderly subjects with hypertension. Stroke. 2008;39:349-354

32. Roberts JL, Clare L, Woods RT. Subjective memory complaints and awareness of memory functioning in mild cognitive impairment: a systematic review. Dement Geriatr Cogn Disord. 2009;28:95-109.

33. Geschwind N. Disconnexion syndrome in animals and man. Brain. 1965;88:237-294.

34. Goldberg E, Bilder RM, Hughes JE, Antin SP, Mattis S. A reticulofrontal disconnection syndrome. Cortex. 1989;25:687-695.

35. Godin O, Doufouil C, Maillard P, et al. White matter lesions as a predictor of depression in the elderly: the 3C-Dijon study. Biol Psychiatry. 2008;63:663-669.

36. Beekman AT, Copeland JR, Prince MJ. Review of community prevalence of depression in later life. Br J Psychiatry. 1999;174:307-311.

metabolic disorders, particularly diabetes. This journal is indexed on PubMed Central and MedLine. The manuscript management system is completely online and includes a very quick and fair peer-review system, which is all easy to use. Visit http://www.dovepress.com/ testimonials.php to read real quotes from published authors. 